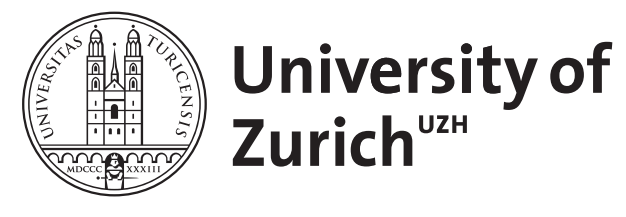

Zurich Open Repository and Archive

University of Zurich

University Library

Strickhofstrasse 39

CH-8057 Zurich

www.zora.uzh.ch

Year: 2013

\title{
Die Passage zur Terra Incognita
}

Neuner-Jehle, S

Posted at the Zurich Open Repository and Archive, University of Zurich ZORA URL: https://doi.org/10.5167/uzh-93667

Journal Article

Published Version

Originally published at:

Neuner-Jehle, S (2013). Die Passage zur Terra Incognita. PrimaryCare, 13(14):248. 


\section{Die Passage zur Terra Incognita}

\section{Ein weiterer kaffeetischphilosophischer Mini-Essay}

Christoph Kolumbus gilt als der Entdecker Amerikas: 1492 landet er mit seiner Mannschaft als Erster auf der Bahamas-Insel San Salvadore, Teil eines bis dahin unbekannten Kontinents, auf den damaligen Landkarte ein riesiger weisser Fleck - Terra incognita. Der Seefahrer Kolumbus am Ziel seiner Wünsche? Mitnichten, war es doch seine Absicht und diejenige der Spanischen Krone, die kürzeste West-Ost-Passage über den Atlantik nach Indien und Japan zu finden, wo gemäss den Berichten des Marco Polo reiche Schätze an Gewürzen und Gold lagern sollten. Ausser freundlichen Ureinwohnern (von ihm also irrtümlich als Indianer bezeichnet) fanden die Spanier nichts dergleichen vor; die teuer ausgerüsteten Abenteurer hatten ihren

Sind wir flexibel genug, unerwartete Entwicklungen als Bereicherung wahrzunehmen? Auftrag also nicht erfüllt. Erst in den folgenden Kolonisationswellen plünderten Seefahrer wie Hojeda und Vespucci den neu entdeckten Kontinent in ihrer Jagd nach Gold, Perlen und Sklaven [1].

Die Passagen in unserem eigenen Leben sind zwar weniger abenteuerlich, aber oft schwierig genug und benötigen Mut: Landen wir wirklich dort, wo wir wollten? Und wenn nicht: Sind wir flexibel genug, unerwartete Entwicklungen als Bereicherung wahrzunehmen? Oder uns ein Scheitern einzugestehen? Und wenn gescheitert: Öffnet uns der Misserfolg neue Türen? Kolumbus schaffte es offenbar nicht und wurde zum Anti-Helden: Nachdem der erste Ruhm der Entdeckung verpufft war, verbitterte er an seinem nicht gestillten Ehrgeiz.

Auch die Medizin kennt Passagen: passagere Besserung, passagere Linderung, passageres Leiden. Manchmal ist die «letzte Passage» zu gehen: Wohin? Ins Paradies, in einen neuen Körper, ins Nichts? Tröstlich dabei ist, dass wir irgendwann wieder dorthin zurückkehren, von wo wir herkommen, nachdem wir einen verschwindend kleinen Beitrag an den Strom der menschlichen Weiterentwicklung geleistet haben. Oder erwartet uns nach dieser letzten Passage ins Jenseits ein traumhaftes Land, Terra incognita, bereit zur Entdeckung?

\section{Buchtipp}

1 Huby F. Traumreisen. Auf den Spuren grosser Entdecker. Stuttgart/ Hamburg/München: Deutscher Bücherbund GmbH; 1980.

\section{Korrespondenz:}

Dr. med. Stefan Neuner-Jehle

$\mathrm{MPH}$, Facharzt für Innere Medizin FMH

Schmidgasse 8, 6300 Zug

sneuner[at]bluewin.ch

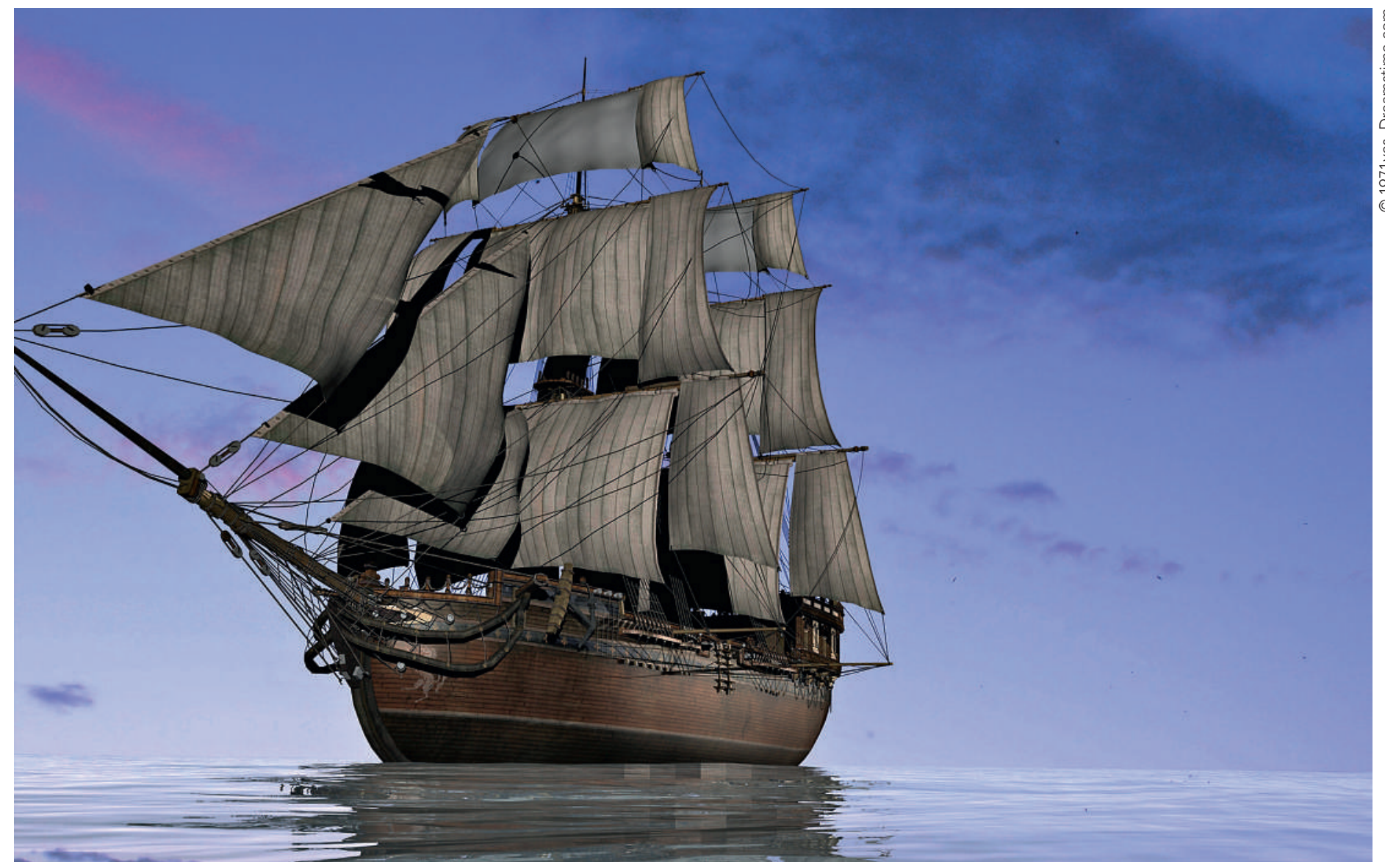

